\title{
Article
}

\section{Is NRXN1 Gene Expression an Important Marker of Treatment of Depressive Disorders? A Pilot Study}

\author{
Aleksandra Skiba ${ }^{1, *, \dagger}$, Monika Talarowska ${ }^{2,+} \mathbb{\infty}$, Janusz Szemraj ${ }^{3} \mathbb{C}$ and Piotr Gałecki ${ }^{1} \mathbb{C}$ \\ 1 Department of Adult Psychiatry, Medical University of Lodz, 91-229 Lodz, Poland; \\ piotr.galecki@umed.lodz.pl \\ 2 Department of Clinical Psychology, Institute of Psychology University of Lodz, 91-433 Lodz, Poland; \\ talarowskamonika@wp.pl \\ 3 Department of Medical Biochemistry, Medical University of Lodz, 92-215 Lodz, Poland; \\ janusz.szemraj@umed.lodz.pl \\ * Correspondence: aleksandra.skiba@umed.lodz.pl \\ + Equal contribution of authors in the compilation of this paper.
}

Citation: Skiba, A.; Talarowska, M.; Szemraj, J.; Gałecki, P. Is NRXN1 Gene Expression an Important Marker of Treatment of Depressive Disorders? A Pilot Study. J. Pers. Med 2021, 11, 637. https://doi.org/ 10.3390/jpm11070637

Academic Editor: Kenneth Blum

Received: 31 March 2021

Accepted: 1 July 2021

Published: 6 July 2021

Publisher's Note: MDPI stays neutral with regard to jurisdictional claims in published maps and institutional affiliations.

Copyright: (c) 2021 by the authors. Licensee MDPI, Basel, Switzerland. This article is an open access article distributed under the terms and conditions of the Creative Commons Attribution (CC BY) license (https:// creativecommons.org/licenses/by/ $4.0 /)$.

\begin{abstract}
Aim: Due to the fact that NRXN1 is associated with neurodevelopmental disorders, the aim of this study was to investigate the role of the NRXN1 gene in the etiology and epigenetics of depression by comparison of NRXN1 mRNA expression and NRXN1 protein level expression in patients suffering from depression versus healthy controls, as well as to search for clinical variables related to expression of the analyzed gene. Material and Methods: A total of 180 people aged 19-64 qualified for the study. The experimental group consisted of 97 people who were psychiatrically hospitalized, diagnosed with recurrent depressive disorders (F33) or who met the diagnostic criteria of a depressive episode (F32) according to ICD-10. The control group included 83 healthy people who volunteered to participate in the study. A sample of peripheral blood was obtained from people who were positively qualified to participate in the study-twice in the experimental group and once in the control group for genetic testing. Sociodemographic variables and data on the course of the disorder were also gathered. Patients were examined on study entry and at the end of the hospitalization with the Hamilton Depression Scale. Obtained data were analyzed statistically. The study was approved by the University's Bioethics Committee. Results: The gene expression of NRXN1 at both mRNA and protein level significantly differs and it is lower in the experimental group compared to expression in healthy people. The difference in gene expression of NRXN1 at both the mRNA and protein levels between the first and second measurement in the experimental group is also significant. The result demonstrates a higher expression level in the first measurement and lower expression level in the second measurement when reported depression symptoms are less severe. Conclusions: Results concerning expression of NRXN1 may play an important role in further researches about the etiopathogenesis of depressive disorders such as looking for depression biomarkers and identifying evidence which may be relevant to personalize treatment for depression.
\end{abstract}

Keywords: depression; NRXN1 gene; expression

\section{Introduction}

Depressive disorders are one of the leading causes of psychiatric hospitalization and one of the leading causes of disability worldwide. Forecasts point to a steady increase in the number of patients, especially in developing countries. Depressive disorders are a serious health problem for patients that often leads to disorganization in their professional, family, and social lives. Depression often appears as a coexisting symptom in other diseases. Conducted clinical trials show that a significant group of people with an initial diagnosis of a depressive episode will have a recurrent course of the disease in the future [1]. About 20\% of patients diagnosed with recurrent depressive disorders (RDD) experience two phases of remission during their lifetime while about $60 \%$ of them experience three or more [2]. 
Currently, it is assumed that the conditions of this disorder are multifactorial: biological, psychological, and social. The biopsychosocial model which includes biomedical and psychosocial approaches, emphasizes their interrelationships and interdependence [3]. The mechanism of inheritance in the etiology of depressive disorders is not sufficiently explained. Family researches, including twin studies, indicate the role of heredity in depressive disorders. The results of the study of monozygotic twins show that the incidence of recurrent depressive disorders ranges from $43 \%$ to $53 \%$ [4]. The complex model of inheritance assumes the interaction of several genes. The studies show that the regions of chromosomes 15q, 17p, and 8p [5,6] as well as 12q23.3-q24.11 and 13q31.1-q31.3 may contain genes associated with depressive disorders [7]. The monoamine hypothesis emphasizes the nature of abnormalities in neurotransmission of serotonin (5-HT), noradrenaline (NA), dopamine (DA), and acetylcholine (ACh) [8,9]. Structural changes in the brain of patients with depressive disorders are characterized by a reduction in volume in the frontal lobes, orbital prefrontal cortex, anterior cingulate cortex, hippocampus, and amygdala $[10,11]$. These regions are directly associated with the symptoms of RDD [12]. In studies on the kynurenine pathway, a decreased level of kynurenic acid was found in the RDD group [13]. The inflammatory theory of depression connects adverse effects of stress with a greater likelihood of depressive symptoms with the influence of hormonal, biochemical, and epigenetic factors. In the RDD group, increased parameters of the active inflammatory process are observed-mainly interleukins 1 and 6, TNF- $\alpha$, and interferon gamma $[14,15]$. A theory that combines the biological, psychological, and environmental factors is the neurodevelopmental theory of depression [16].

Neurexins are presynaptic adhesive proteins that play a role in connecting neurons at the synapse. They consist of three genes: NRXN1, NRXN2, and NRXN3. They are mostly located on the presynaptic membrane and contain a single transmembrane domain [17]. They nucleate the trans-synaptic signaling network that assists the properties of synapses and are susceptible to impairments in neuropsychiatric disorders. Mutations in genes encoding neurexins are associated with Tourette syndrome, autism, and schizophrenia [18]. Other research shows the relationship between neurexins and impulsive behavior as well as alcohol dependence [19]. Neurexin 1 (NRXN1) is a protein responsible for synaptic homeostasis, development of glutamatergic and GABAergic synapses, balance of stimulation, and inhibition of synaptic formation and functioning in the central nervous system [20]. Research suggests that NRXN1 is associated with neurodevelopmental disorders characterized by abnormalities in synaptic transmission, such as autism and intellectual disability. Levels of NRXN1 expression in the prefrontal cortex are changed in schizophrenia and bipolar disorder in comparison to healthy people. Studies suggest that NRXN1 expression is the highest in the human prefrontal cortex during critical developmental moments. It is associated with the onset and diagnosis of a range of neurodevelopmental disorders and may be an important variable in neuropsychiatric disorders [21]. Another studies confirm the importance of exon deletion near the $5^{\prime}$ end of NRXN1 in the expression of neurodevelopmental disorders [22]. For a child with Pitt-Hopkins syndrome, the heterozygosity for two mutations in the NRXN1 gene was identified [23]. Studies in groups of patients diagnosed with autism spectrum disorder confirm the NRXN1 mutations in sick sibling pairs [24,25]. Loss of heterozygosity for NRXN1 and NRXN2 in mice leads to phenotypes associated with autism and schizophrenia [26]. A $380 \mathrm{~kb}$ deletion of NRXN1 occurred in a woman with Asperger's syndrome, anxiety, and depression as well as in four of her children diagnosed with autism, anxiety disorders, developmental delay, and speech delay. This change was not observed in her healthy child [27]. Research indicates that peripheral blood determinations which are expressed at the mRNA level and at the protein level for genes largely reflect the expression in the central nervous system [28].

Due to this fact, the aim of the study was to verify the expression of gene NRXN1 at the mRNA and protein level in patients suffering from depression versus healthy controls, as well as to search for clinical variables related to expression of the analyzed gene. The purpose of the study was also to investigate the role of the NRXN1 gene in the etiology and 
epigenetics of depression. It may help to make the correct diagnosis, look for depression biomarkers and to identify evidence which may be relevant to personalize treatment for depression such as targeted therapies, especially in treatment-resistant depression.

\section{Material}

A total of 180 people aged 19-64 were qualified and took part in the study (mean: $\mathrm{M}=38.25$; standard deviation: $\mathrm{SD}=10.01$; median: $\mathrm{Me}=35)$, included 119 women $(66 \%$, aged 19-64; $\mathrm{M}=38.27 ; \mathrm{SD}=12.25 ; \mathrm{Me}=36)$ and $61 \mathrm{men}(34 \%$, aged 19-62; $\mathrm{M}=38.21$; $\mathrm{SD}=14.50 ; \mathrm{Me}=32$ ).

The experimental group (DD) consisted of 97 people who were psychiatrically hospitalized, diagnosed with recurrent depressive disorders (F33) or who met the diagnostic criteria of depressive episode (F32) according to ICD10. The experimental group included people aged 19-64 $(\mathrm{M}=43.22 ; \mathrm{SD}=12.78 ; \mathrm{Me}=46)$, included 64 women $(66 \%$, aged 19-64; $\mathrm{M}=42.23 ; \mathrm{SD}=12.05 ; \mathrm{Me}=45)$ and 33 men $(34 \%$, aged 19- 62; $\mathrm{M}=45.12 ; \mathrm{SD}=14.09$; $\mathrm{Me}=51)$.

The control group (CG) consisted of 83 healthy people who volunteered to participate in the study. The control group included people aged 20-60 ( $\mathrm{M}=32.45 ; \mathrm{SD}=10.73 ; \mathrm{Me}=28)$, included 55 women $(66 \%$, aged $20-60 ; \mathrm{M}=33.65 ; \mathrm{SD}=10.86 ; \mathrm{Me}=29)$ and 28 men $(34 \%$, aged 20-58; $\mathrm{M}=30.07 ; \mathrm{SD}=10.25 ; \mathrm{Me}=27$ ).

Table 1 consist of basic information about people who took part in the study.

Table 1. Demographic characteristics: experimental and control group.

\begin{tabular}{|c|c|c|c|c|c|}
\hline Variable & $\mathbf{N}$ & Age & Age $M$ & Age SD & Age Me \\
\hline Total group & 180 & $19-64$ & 38.25 & 10.01 & 35 \\
\hline Total group-women & $119(66 \%)$ & $19-64$ & 38.27 & 12.25 & 36 \\
\hline Total group-men & $61(34 \%)$ & $19-62$ & 38.21 & 14.50 & 32 \\
\hline Experimental group & 97 & $19-64$ & 43.22 & 12.75 & 46 \\
\hline Experimental group-women & $64(66 \%)$ & $19-64$ & 42.23 & 12.05 & 45 \\
\hline Experimental group-men & $33(34 \%)$ & $19-62$ & 45.12 & 14.09 & 51 \\
\hline Control group & 83 & $20-60$ & 33.65 & 10.86 & 29 \\
\hline Control group-women & $55(66 \%)$ & $20-60$ & 33.65 & 10.86 & 29 \\
\hline Control group-men & $28(34 \%)$ & $20-58$ & 30.07 & 10.25 & 27 \\
\hline
\end{tabular}

$\mathrm{N}$-number; $\mathrm{M}$-mean; SD—standard deviation; Me—median.

Patients suffering from depression who were additionally diagnosed with other mental disorders, addictions, traumatic central nervous system injuries, severe neurological and chronic inflammatory diseases were excluded from the study. The same rules of exclusion were also applied to the control group. Data on the illness course (duration of the disease, number of hospitalizations, and number of episodes) were obtained using the Composite International Diagnostic Interview (CIDI). In addition, information about sociodemographic variables (age, sex, education, and place of residence) was collected. Severity of depression at inclusion to the study and at the end of hospitalization was evaluated using the Hamilton Depression Rating Scale (HDRS) for DD. A sample of peripheral blood was obtained from people who were positively qualified to participate in the study - twice in the experimental group (at the beginning and end of hospitalization) and once in the control group for genetic testing. The aim of double blood sampling in the experimental group was to verify if the expression of the studied gene may change when the improvement in mental state was expected and reported depression symptoms were less severe. It was also related to the end of treatment in the hospital. All of the patients were treated with typical antidepressant treatment, mostly with SSRIs (selective serotonin reuptake inhibitor). All obtained data were analyzed statistically. The study was approved by the University's Bioethics Committee. All study participants were familiarized with the information about the study, have given an informed consent to participate in the research. 
They could withdraw it at any stage of the study without any consequences, including further treatment in the experimental group.

\section{Methods}

Total RNA isolation from the patients' peripheral blood mononuclear cells was performed with the use of InviTrap Spin Universal RNA Kit (Stratec molecular, Berlin, Germany) in accordance with the manufacturer's recommendations. Absorbance of isolated RNA was measured using a spectrophotometer (Picodrop ${ }^{\mathrm{TM}}$ Microliter Spectrophotometer VWR International, LLC, Radnor, PA, USA) at $\lambda=260 \mathrm{~nm}$ in order to determine total RNA concentration. The quality of total RNA was checked with Agilent RNA 6000 Nano Kit (Agilent Technologies, Santa Clara, CA, USA) in accordance with the manufacturer's recommendations. The real-time PCR reaction was conducted using TaqMan ${ }^{\circledR}$ RNA Reverse Transcription Kit (Applied Biosystems, Waltham, MA, USA) in accordance with the manufacturer's recommendations. To calculate relative expression of mRNA genes, the $\mathrm{Ct}$ comparative method was used [29].

Concentration of NRXN1 protein in the serum of patients and controls was determined by ELISA testing, using the Human NRXN1 Elisa kit (MyBiosource, San Diego, CA, USA) in accordance with the manufacturer's recommendations. $\beta$-actin was used as endogenous control of protein concentrations in the samples and was labeled with Human Actin Beta Kit (ACTb) ELISA Kit (BMASSAY, HaiDian District, Beijing China) in accordance with the manufacturer's recommendations.

The 17-item Hamilton Depression Rating Scale (HDRS) was used to assess the severity of depressive disorder in the experimental group. The severity of symptoms was assessed on a four-point scale (from 0 to 4 points in 13 items and from 0 to 2 points for the rest) [30,31].

Obtained data were analyzed statistically using the STATISTICA PL, version 13.1 (TIBCO Software, Palo Alto, CA, USA). The statistically significant differences were considered at $p<0.05$. Selected descriptive and statistical inference methods were used to compile the data. The arithmetic mean (M), median (Me), and standard deviation (SD) were calculated. The Shapiro-Wilk test was used to assess the normality of the variables' distribution. $T$-test or Mann-Whitney $U$ test were used to compare the gene expression at the mRNA and protein levels. A T-test was also used to compare the degree of depression in the RDD group between the measurements. The Spearman's rank correlation coefficient and regression analysis methods were used to study relationship between variables. ANOVA was used to compare pairs of dependent and independent variables.

\section{Results}

A statistically significant difference was found in expression of the NRXN1 gene at the mRNA level in the experimental group-DD and the control group-CG. Expression of the NRXN1 gene at the mRNA level is significantly lower in the DD group than in the CG $(p=0.001)$. The difference in expression of the NRXN1 gene at the protein level also turned out to be statistically significant. Expression of the NRXN1 gene at the protein level is significantly lower in the DD group than in the CG $(p=0.001)$. The results of gene expression are described in Table 2 and on Figure 1 where all significant differences are presented.

Table 2. Expression of the NRXN1 gene in the examined groups.

\begin{tabular}{ccccccccc}
\hline Variable & M DD & M CG & $t$ & $p$ & N DD & N CG & SD DD & SD CG \\
\hline NRXN11m_RQmRNA & 0.11 & 0.14 & -5.589 & $0.001^{*}$ & 97 & 83 & 0.053 & 0.018 \\
\hline NRXN11m_ng_protein & 1.19 & 1.68 & -11.151 & $0.001^{*}$ & 97 & 83 & 0.341 & 0.221 \\
\hline
\end{tabular}

NRXN11m_RQmRNA—NRXN1 expression in 1 measurement mRNA level (RQ); NRXN11m_ng_protein—NRXN1 expression in 1 measurement protein level $(\mathrm{ng} / \mathrm{mL})$; $\mathrm{DD}$ —experimental group (group of patients with depressive disorders); $\mathrm{CG}$-control group; $\mathrm{N}$-sample; $p$-level of statistical significance (* statistically significant $p<0,05)$; SD—standard deviation; $t$ —value of $t$-test; $\mathrm{M}$-mean. 


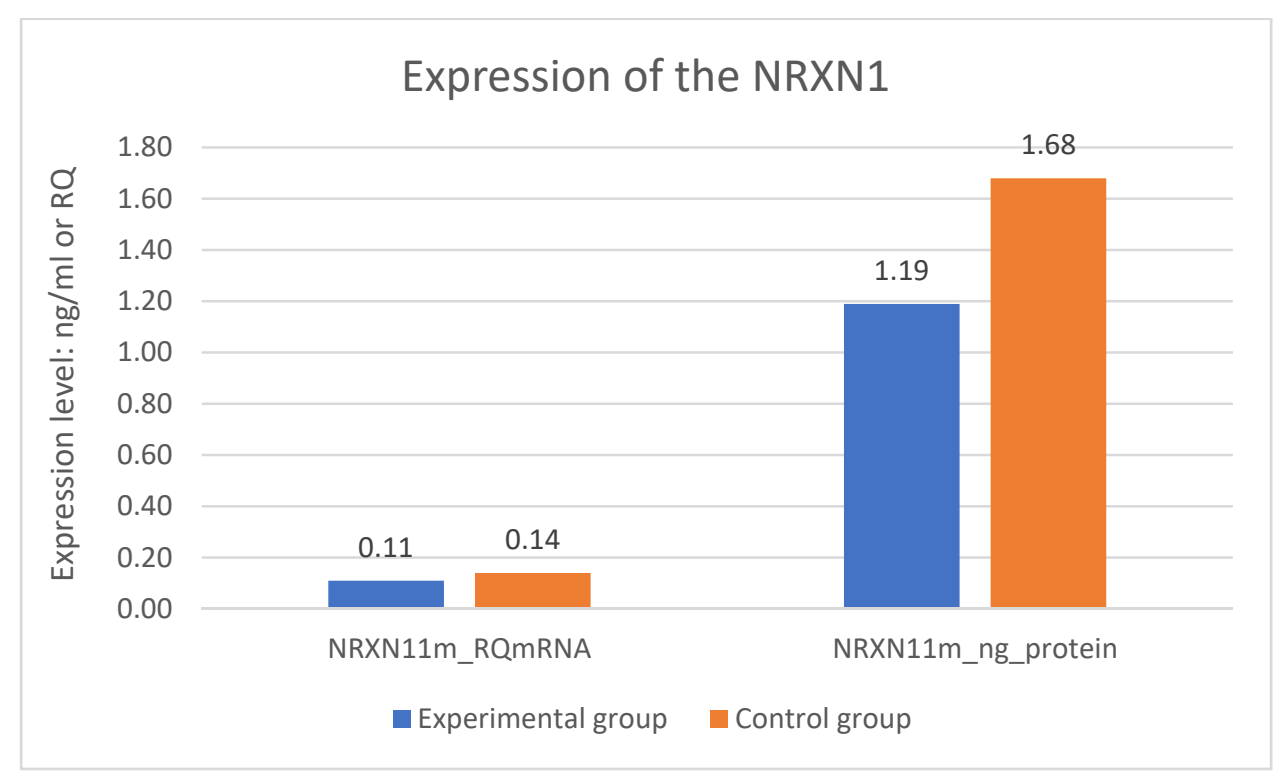

Figure 1. Expression of the NRXN1 gene in the examined groups.

To extend the previously presented results, the analysis of the relationship between expression of the studied gene on both levels in the experimental group was conducted. It shows a significant correlation between expression of the NRXN1 gene at the protein level and a significant correlation between expression of the same gene at the mRNA level. This is a weak positive correlation. The greater expression of the NRXN1 gene at the protein level, the greater expression of this gene at the mRNA level (Spearman's rank correlation coefficient $=0.28 ; p<0.05)$.

What is more, the analysis of the relationship between expression of the studied gene in the control group shows a significant correlation between expression of the NRXN1 gene at the protein level and expression of the same gene at the mRNA level. This is a very strong positive correlation. The greater expression of the NRXN1 gene at the protein level, the greater expression of this NRXN1 gene at the mRNA level (Spearman's rank correlation coefficient $=0.95 ; p<0.05$ ).

The division of both research groups in terms of age revealed significant difference related to expression of the NRXN1 gene at the protein level. Expression of the NRXN1 gene is significantly higher in the younger group of respondents $(p=0.004)$. The metric variable "age" was divided into two groups according to the median. The results are described on the Figure 2.

There is no significant relationship between expression of the studied gene and sex. There is also no significant relationship between clinical variables and expression of the studied gene in DD group.

The division of DD group in terms of age revealed significant differences related to the severity of depression symptoms. The metric variable "age" was divided into two groups according to the median. In both measurements (number $1 p=0.001$; number $2 p=0.020$ ), the results of the HDRS test are higher in the older group of respondents-greater severity of symptoms. The results are described in Figures 3 and 4 .

The division of DD group in terms duration of the disease revealed significant difference related to the severity of depression symptoms. The metric variable "disease duration" was divided into two groups according to the median. The result of the HDRS test in the first measurement is higher in the group with a shorter disease duration $(p=0.004)$. The results are described on Figure 5.

There is no significant result of an influence of sociodemographic and clinical course variables on expression of NRXN1 gene at both mRNA and protein levels in the DD group in the second measurement. 
The results of the relationship between expression of NRXN1 gene in the DD group from the first and second measurement revealed statistically significant, positive correlations. Expression of NRXN1 in the first measurement at the mRNA level correlates with expression of NRXN1 in the second measurement at the mRNA level and at the protein level. Both relationships are weak (Spearman's rank correlation coefficient $=0.28$ for both; $p<0.05)$.

Expression of NRXN1 in the first measurement at the protein level correlates with expression of NRXN1 in the second measurement at the mRNA level and at the protein level. Both relationships are very strong (Spearman's rank correlation coefficient $=0.89$ and $0.88 ; p<0.05)$.

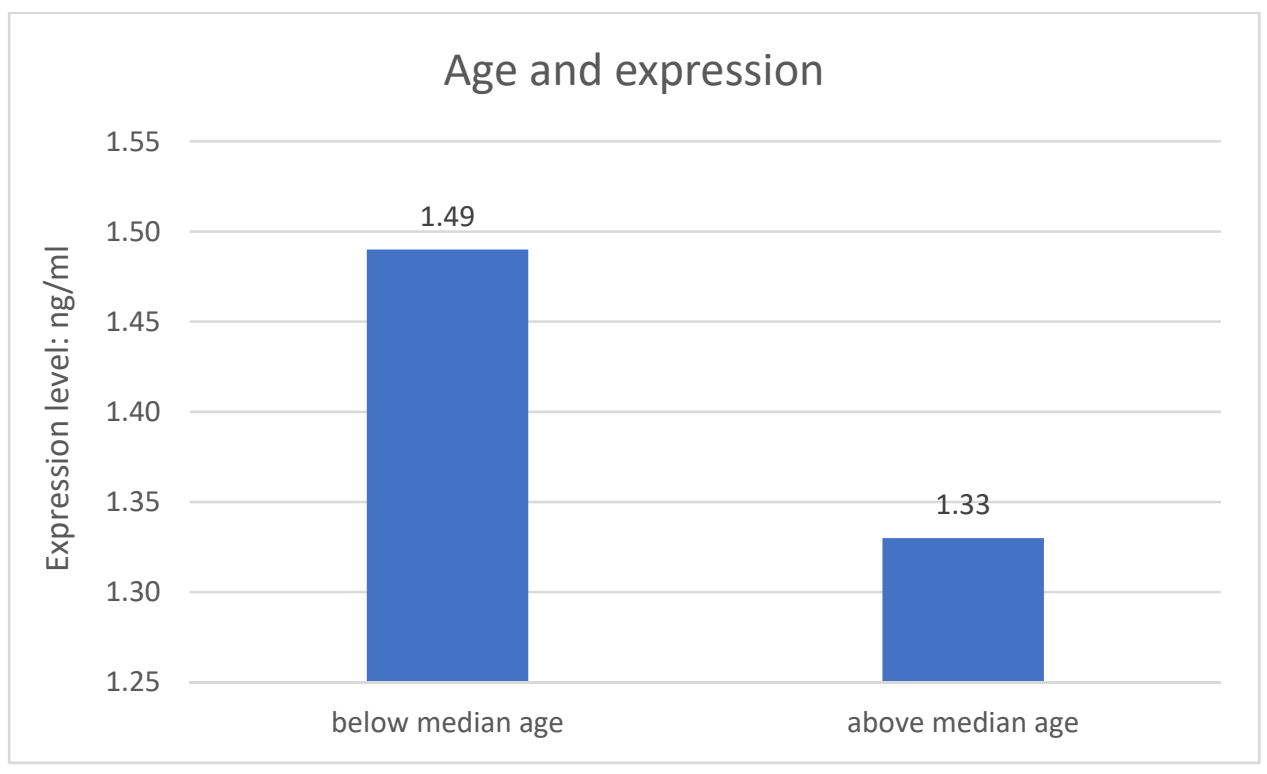

Figure 2. Age and expression of the studied gene.

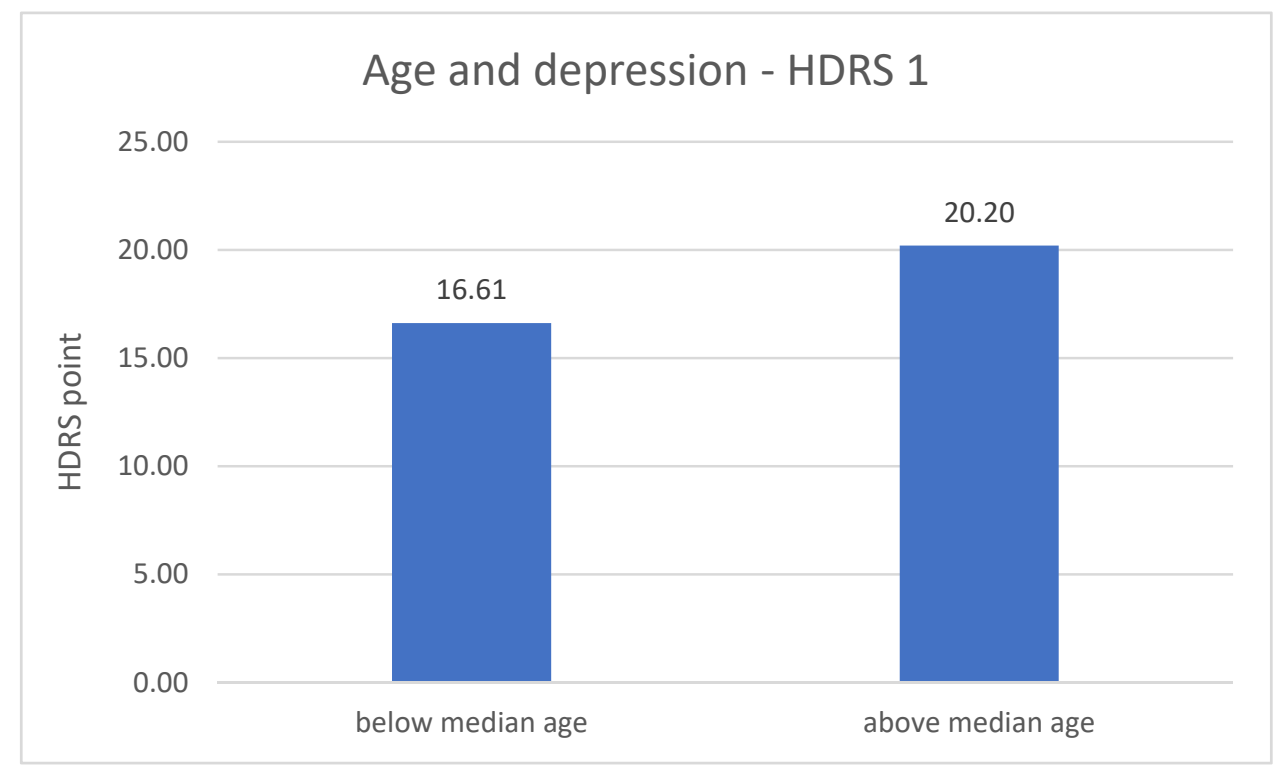

Figure 3. Age and the severity of depression-HDRS 1 measurement. 


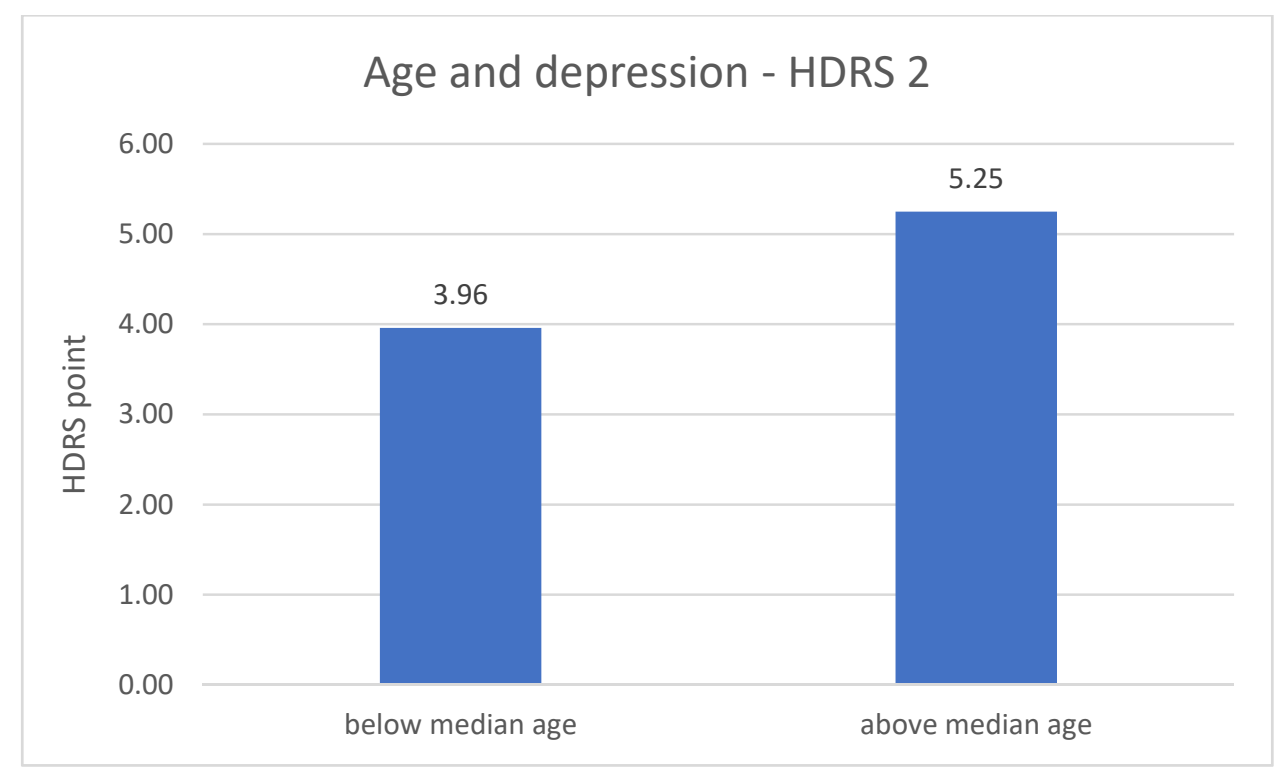

Figure 4. Age and the severity of depression-HDRS 2 measurement.

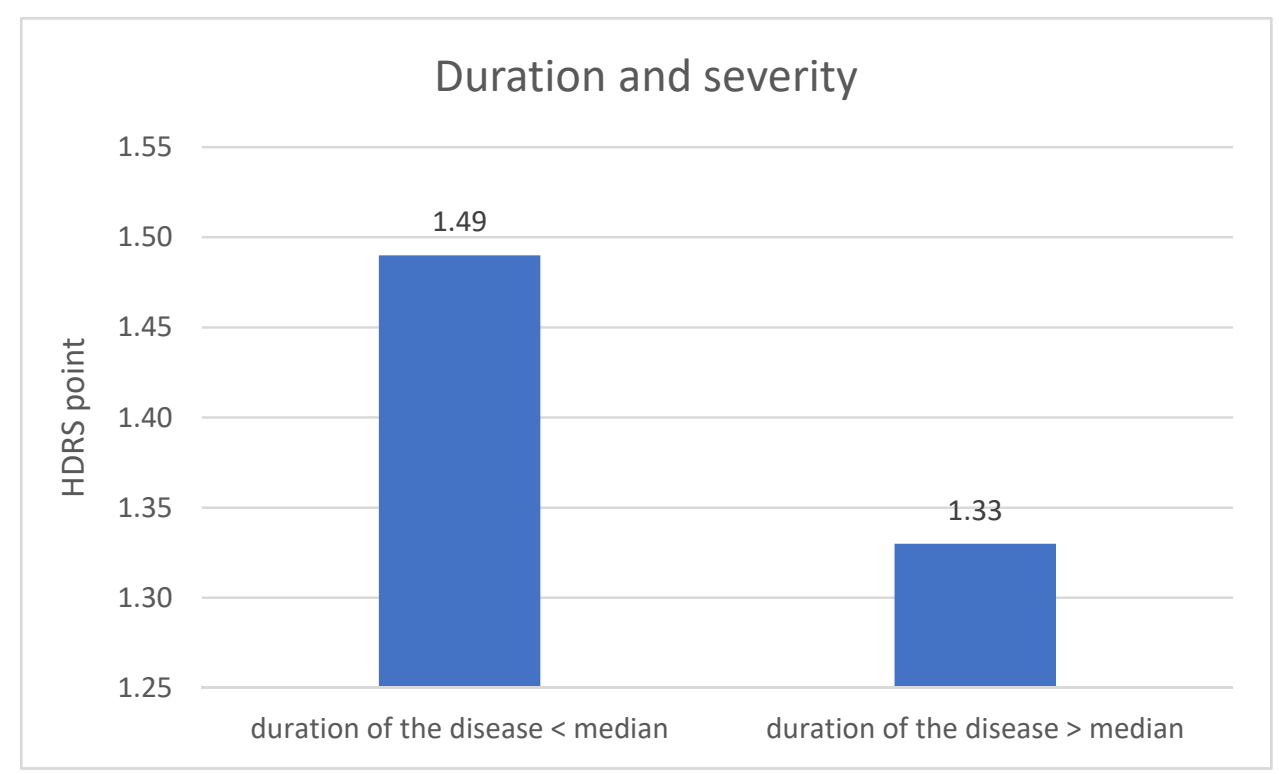

Figure 5. Duration of the disease and the severity of depression-1 measurement.

Paired difference tests between the measurements were also performed. The following relationships were found:

- $\quad$ NRXN1 expression at the mRNA (RQ) level—second measurement $>$ first measurement

- $\quad$ NRXN1 expression at the protein level $(\mathrm{ng} / \mathrm{mL})$ - second measurement $>$ first measurement

The results are described in Table 3.

In order to assess which factors significantly influenced expression level of the studied gene in the groups, a regression analysis was performed for expression of NRXN1 at the protein level with two predictors-expression of NRXN1 at the mRNA level and depression morbidity (group). A statistically significant result is obtained which indicated that the presence of depression and expression of the NRXN1 gene at the mRNA level are significant predictors of expression of the NRXN1 gene at the protein level $(p=0.001$; standard error $\mathrm{BETA}=0.058$; confidence interval $=0.95$ ). All the results are described in Table 4 . 
Table 3. Results of paired difference tests between the measurements of the expression of the studied gene in the experimental group.

\begin{tabular}{ccccc}
\hline Variable & $\begin{array}{c}\text { M 1st } \\
\text { Measurement }\end{array}$ & $\begin{array}{c}\text { SD 1st } \\
\text { Measurement }\end{array}$ & $\begin{array}{c}\text { M 2st } \\
\text { Measurement }\end{array}$ & $\begin{array}{c}\text { SD 2st } \\
\text { Measurement }\end{array}$ \\
\hline $\begin{array}{l}\text { NRXN11m_RQmRNA: } \\
\text { NRXN12m_RQmRNA: }\end{array}$ & 0.107 & 0.053 & 0.118 & 0.024 \\
\hline $\begin{array}{l}\text { NRXN11m_ng_protein: } \\
\text { NRXN12m_ng_protein: }\end{array}$ & 1.191 & 0.341 & 1.402 & 0.298 \\
\hline
\end{tabular}

NRXN11m_RQmRNA—NRXN1 expression in 1 measurement mRNA level (RQ); NRXN11m_ng_protein—NRXN1 expression in 1 measurement protein level (ng/mL); NRXN12m_RQmRNA—NRXN1 expression in 2 measurement mRNA level (RQ); NRXN12m_ng_proteinNRXN1 expression in 2 measurement protein level (ng/mL); SD—standard deviation; $\mathrm{M}$-mean.

Table 4. Variable regression summary-expression of the studied gene in the examined groups including predictors: expression of the studied gene at the mRNA level and the occurrence of depression.

\begin{tabular}{ccccccc}
\hline Variable & Predictor & $\mathbf{R}$ & $\mathbf{R}^{2}$ & SR $^{2}$ & F & $p$ \\
\cline { 1 - 2 } NRXN11m_ng_protein & Depression & 0.70 & 0.49 & 0.49 & 86.43 & $0.001 *$ \\
\cline { 2 - 2 } & NRXN11m_RQmRNA & & & & \\
\hline
\end{tabular}

NRXN11m_RQmRNA—NRXN1 expression in 1 measurement mRNA level (RQ); NRXN11m_ng_protein—NRXN1 expression in 1 measurement protein level (ng/mL); F-F statistic value; $p$-level of statistical significance ( ${ }^{*}$ statistically significant $\left.p<0,05\right)$; R—value of the regression coefficient; $\mathrm{R}^{2}$-squared regression coefficient; $\mathrm{SR}^{2}$ —standardized $\mathrm{R}^{2}$.

Significantly lower result in the DD group of the HDRS test in the second measurement was found when comparing to the results from the first measurement $(p=0.001)$. The result is described in Table 5 and in Figure 6.

Table 5. Severity of depression in the experimental group -1 and 2 measurement.

\begin{tabular}{ccccccc}
\hline Variable & $\begin{array}{c}\text { HDRS_I } \\
\text { M DD }\end{array}$ & $\begin{array}{c}\text { HDRS_I } \\
\text { SD DD }\end{array}$ & $\begin{array}{c}\text { HDRS_II } \\
\text { M DD }\end{array}$ & $\begin{array}{c}\text { HDRS_II } \\
\text { SD DD }\end{array}$ & F & $p$ \\
\hline $\begin{array}{l}\text { HDRS_I: } \\
\text { HDRS_II }\end{array}$ & 18.97 & 6.63 & 4.81 & 3.93 & 270.248 & $0.001^{*}$ \\
\hline
\end{tabular}

HDRS_I-Hamilton Depression Rating Scale 1 measurement; HDRS_II—Hamilton Depression Rating Scale 2 measurement; DD — experimental group (group of patients with depressive disorders); SD—standard deviation; $\mathrm{M}-$ mean; F-F statistic value; $p$-level of statistical significance $\left({ }^{*}\right.$ statistically significant $\left.p<0,05\right)$.

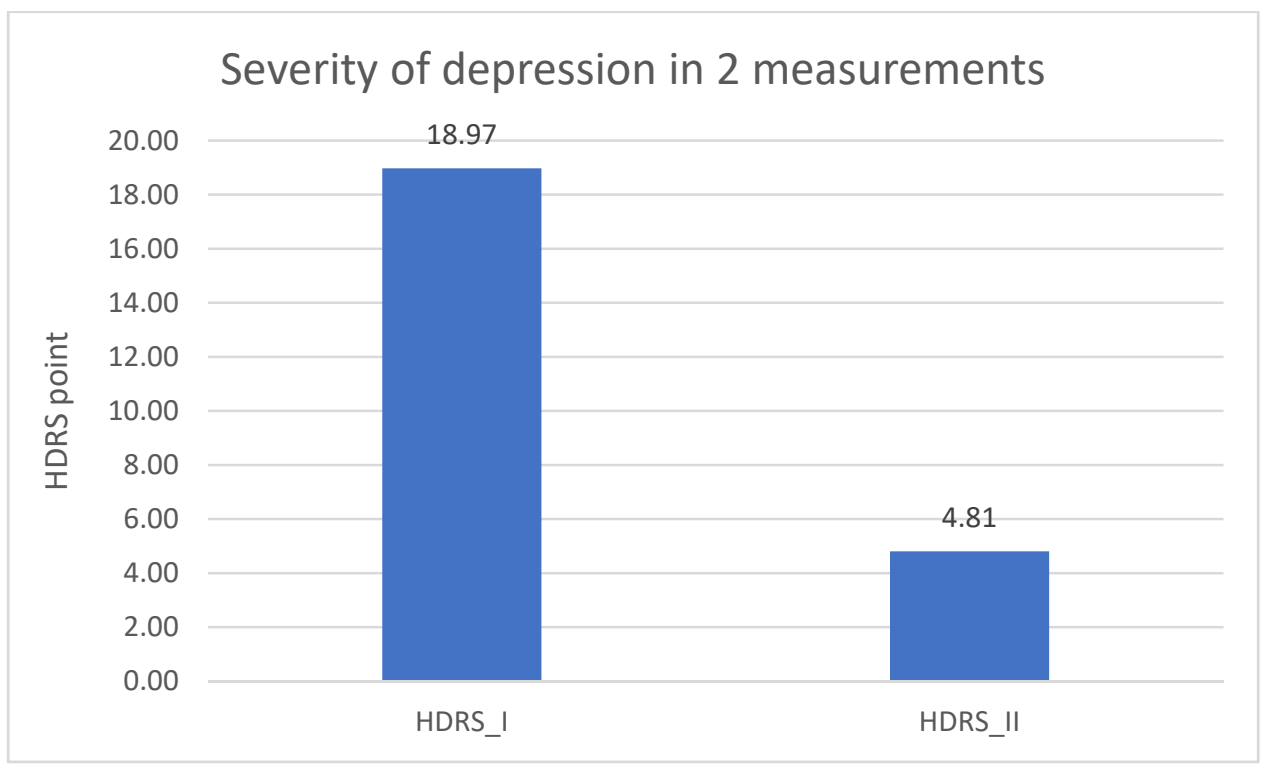

Figure 6. Severity of depression in the experimental group -1 and 2 measurement. 


\section{Discussion}

The scientific literature contains no specific research results and scientific reports about expression of the NRXN1 gene in the group of patients diagnosed with depressive disorders. There are few results concerning other mental disorders-ASD, Pitt-Hopkins syndrome, schizophrenia, or intellectual disability [32]. Kirov et al. in their research prove that the deletions of NRXN1 confer a substantial increase in the risk of schizophrenia [33]. The differences in the level of NRXN1 in comparison with reported data from researches in patients with schizophrenia and bipolar disorder [34] may be due to the fact that depression is a common disease in the population and characterized by a heterogeneous etiology, i.e., there are also differences in the contribution of genetic factors of depression. Moreover, NRXN1 and NLGN3 are differentially expressed in the cerebral cortex and hippocampus in study in mice, which may be responsible for the changes in synaptic plasticity during aging associated with neuroplasticity [35]. This may have an impact on the potential neurexin depletion in depression and its influence on the synaptic machinery in depression development.

This study showed that the expressions of the NRXN1 gene at both mRNA and protein levels in patients with recurrent depressive disorders significantly differ from the expressions of this gene in the health control group. Expression was lower in the group of patients with depressive disorders. However, another study shows the increases in NRXN1- $\alpha$ and $\beta$ expression in bipolar disorder and schizophrenia [21]. The relationships of mutations and expression of the NRXN1 gene published in the literature confirm its importance in neurodevelopmental and neuropsychiatric disorders [36,37] so this may be a significant indication of its importance in depressive disorders. Another important finding is the demonstration of significant relationships between the expression of the studied gene in the experimental group. The greater the expression of the NRXN1 gene at the protein level, the greater the expression of this gene at the mRNA level. Interestingly, the same relationship was shown for the NRXN1 gene in the control group. However, there is no possibility of comparison results for a selected gene in the group of patients with depressive disorders in the available scientific literature. Studies concerning the effect of NRXN polymorphisms and clozapine treatment in the group of patients with schizophrenia show its deletion [38,39]. Research by Lam et al. proves that NRXN1-alpha plays an important role for the efficient establishment of neural stem cells as well as in neuronal differentiation while differentiated cells from healthy control individuals and an individual with autism spectrum disorder carrying bi-allelic NRXN1-alpha deletion [40].

Then, significant relationships were demonstrated between NRXN1 expression in the first and second measurement. The relationships turned out to be positive. Expression level was higher in the second measurement. Selected data collected from the respondents on sociodemographic variables also turned out to be significant with the expression of the studied gene in the experimental and control group. The differences in expression were statistically significant when the whole study group was divided by age. In the further part of the study, it was shown that the occurrence of depression and the expression of the NRXN1 gene at the mRNA level were significant predictors of the expression of the NRXN1 gene at the protein level.

The last research aim was to compare the severity of depression in the experimental group between the measurements and to assess the impact of other sociodemographic variables. Significantly lower results of the HDRS test in the second measurement compared to the results from the first measurement were found. This may indicate an important improvement in the mental state in the experimental group. What is more, this influence may be linked to the conclusions regarding the differences between expression of NRXN1 in both measurements in the experimental group. Furthermore, in both measurements, the results of the HDRS test were higher in the older group of respondents, which may indicate an increase in the severity of depressive symptoms with age, what is associated with an increasingly frequent diagnosis of depression in the elderly and decreased quality 
of life in this group [41]. The results of the HDRS test in the first measurement were higher in the group of respondents with a shorter disease duration.

\section{Conclusions}

Gene expression of NRXN1 at both mRNA and protein levels may play an important role in the etiopathogenesis of depressive disorders and these expressions significantly differ from the expressions of these genes in healthy people. These conclusions can encourage research into further studies that are oriented to new methods of prevention, diagnosis, and treatment of depression.

\section{Limitations}

The most important limitation of this study is the significant age difference between the experimental and control group which could have influenced the analyses performed. It would be worth verifying the significant relationships in the next study with a larger and proportional research group as well as using respondent-driven sampling (RDS) as an example of statistical method. A significant limitation may also be the possibility of qualifying people with co-morbidity affecting the obtained results, although exclusion criteria were also applied upon inclusion. It should be added that the survey and interview were carried out to minimize this risk. It would also be worthwhile to verify whether the specific applied pharmacological treatment or the combination with psychotherapy may also affect the expression of the studied gene.

Author Contributions: Conceptualization, A.S. and M.T.; methodology, A.S. and J.S.; formal analysis, A.S.; investigation, A.S.; data curation, P.G.; writing-original draft preparation, A.S.; writingreview and editing, A.S. and M.T.; supervision, M.T.; project administration, M.T. and P.G.; funding acquisition, P.G. All authors have read and agreed to the published version of the manuscript.

Funding: This study was supported by the funds of the Medical University of Lodz, Poland [grant number 502-03/5-062-02/502-54-223-18].

Institutional Review Board Statement: The study was conducted according to the guidelines of the Declaration of Helsinki, and approved by Bioethical Committee of the Medical University of Lodz (protocol No. RNN/328/18/KE; 16 October 2018).

Informed Consent Statement: Informed consent was obtained from all subjects involved in the Study.

Data Availability Statement: The data analyzed in the study are available upon request to the authors of the article.

Conflicts of Interest: The authors have no conflict of interest to declare.

\section{References}

1. Kessler, R.C.; Bromet, E.J. The epidemiology of depression across cultures. Annu. Rev. Public Health 2013, 34, 119-138. [CrossRef]

2. Mead, G.E.; Morley, W.; Campbell, P.; Greig, C.A.; McMurdo, M.; Lawlor, D.A. Exercise for depression. Cochrane Database Syst. Rev. 2008, 8, CD004366.

3. Garcia-Toro, M.; Aguirre, I. Biopsychosocial model in depression revisited. Med. Hypotheses 2007, 68, 683-691. [CrossRef]

4. Middeldorp, C.M.; Cath, D.C.; Van Dyck, R.; Boomsma, D.I. The co-morbidity of anxiety and depression in the perspective of genetic epidemiology. A review of twin and family studies. Psychol. Med. 2005, 35, 611-624. [CrossRef]

5. Holmans, P.; Weissman, M.M.; Zubenko, G.S.; Scheftner, W.A.; Crowe, R.R.; Depaulo, J.R.; Knowles, J.A.; Zubenko, W.N.; Murphy-Eberenz, K.; Marta, D.H.; et al. Genetics of recurrent early-onset major depression (GenRED): Final genome scan report. Am. J. Psychiatry 2007, 164, 248-258. [CrossRef]

6. Levinson, D.F.; Evgrafov, O.V.; Knowles, J.A.; Potash, J.B.; Weissman, M.M.; Scheftner, W.A.; DePaulo, J.R.; Crowe, R.R.; MurphyEberenz, K.; Marta, D.H.; et al. Genetics of recurrent early-onset major depression (GenRED): Significant linkage on chromosome 15q25-q26 after fine mapping with single nucleotide polymorphism markers. Am. J. Psychiatry 2007, 164, 259-264. [CrossRef]

7. McGuffin, P.; Knight, J.; Breen, G.; Brewster, S.; Boyd, P.R.; Craddock, N.; Gill, M.; Korszun, A.; Maier, W.; Middleton, L.; et al. Whole genome linkage scan of recurrent depressive disorder from the Depression Network study. Hum. Mol. Genet. 2005, 14, 3337-3345. [CrossRef]

8. López-Muñoz, F.; Alamo, C. Monoaminergic neurotransmission: The history of the discovery of antidepressants from 1950s until today. Curr. Pharm. Des. 2009, 15, 1563-1586. [CrossRef] 
9. Goldberg, J.; Bell, C.E.; Pollard, D.A. Revisiting the monoamine hypothesis of depression: A new perspective. Perspect. Med. Chem. 2014, 3, 1-8. [CrossRef]

10. Whittle, S.; Lichter, R.; Dennison, M.; Vijayakumar, N.; Schwartz, O.; Byrne, M.L.; Simmons, J.G.; Yücel, M.; Pantelis, C.; McGorry, P.; et al. Structural brain development and depression onset during adolescence: A prospective longitudinal study. Am. J. Psychiatry 2014, 171, 564-571. [CrossRef]

11. Zhang, F.-F.; Peng, W.; Sweeney, J.A.; Jia, Z.-Y.; Gong, Q.-Y. Brain structure alterations in depression: Psychoradiological evidence. CNS Neurosci. Ther. 2018, 24, 994-1003. [CrossRef]

12. Singh, M.K.; Gotlib, I.H. The Neuroscience of Depression: Implications for Assessment and Intervention. Behav. Res. Ther. 2014, 62, 60-73. [CrossRef]

13. Myint, A.M.; Kim, Y.K.; Verkerk, R.; Scharpe, S.; Steibusch, H.; Leonard, B. Kynurenine pathway in major depression: Evidence of impaired neuroprotection. J. Affect. Disord. 2007, 98, 143-151. [CrossRef]

14. Talarowska, M.; Szemraj, J.; Berk, M.; Maes, M.; Gałecki, P. Oxidant/antioxidant imbalance is an inherent feature of depression. BMC Psychiatry 2015, 15, 71. [CrossRef]

15. Gałecki, P.; Talarowska, M. Inflammatory theory of depression. Psychiatr. Pol. 2018, 52, 437-447. [CrossRef]

16. Gałecki, P.; Talarowska, M. Neurodevelopmental theory of depression. Prog. Neuropsychopharmacol. Biol. Psychiatry 2018, 80, 267-272. [CrossRef]

17. Chen, F.; Venugopal, V.; Murray, B.; Rudenko, G. The structure of neurexin $1 \alpha$ reveals features promoting a role as synaptic organizer. Structure 2011, 19, 779-789. [CrossRef]

18. Südhof, T.C. Synaptic neurexin complexes: A molecular code for the logic of neural circuits. Cell 2017, 171, 745-769. [CrossRef]

19. Stoltenberg, S.F.; Lehmann, M.K.; Christ, C.C.; Hersrud, S.L.; Davies, G.E. Associations among types of impulsivity, substance use problems and neurexin-3 polymorphisms. Drug Alcohol Depend. 2011, 119, e31-e38. [CrossRef]

20. Zhang, C.; Atasoy, D.; Araç, D.; Yang, X.; Fucillo, M.V.; Robison, A.J.; Ko, J.; Brunger, A.T.; Südhof, T.C. Neurexins Physically and Functionally Interact with GABAA-receptors. Neuron 2010, 66, 403-416. [CrossRef]

21. Jenkins, A.K.; Paterson, C.; Wang, Y.; Hyde, T.M.; Kleinman, J.E.; Law, A.J. Neurexin 1 (NRXN1) Splice Isoform Expression During Human Neocortical Development and Aging. Mol. Psychiatry 2016, 21, 701-706. [CrossRef]

22. Lowther, C.; Speevak, M.; Armour, C.M.; Goh, E.S.; Graham, G.E.; Li, C.; Zeesman, S.; Nowaczyk, M.J.; Schultz, L.A.; Morra, A.; et al. Molecular characterization of NRXN1 deletions from 19,263 clinical microarray cases identifies exons important for neurodevelopmental disease expression. Genet. Med. 2017, 19, 53-61. [CrossRef] [PubMed]

23. Zweier, C.; de Jong, E.K.; Zweier, M.; Orrico, A.; Ousager, L.B.; Collins, A.L.; Bijlsma, E.K.; Oortveld, M.A.; Ekici, A.B.; Reis, A.; et al. CNTNAP2 and NRXN1 are mutated in autosomal-recessive Pitt-Hopkins-like mental retardation and determine the level of a common synaptic protein in Drosophila. Am. J. Hum. Genet. 2009, 85, 655-666. [CrossRef] [PubMed]

24. Szatmari, P.; Paterson, A.D.; Zwaigenbaum, L.; Roberts, W.; Brain, J.; Liu, X.-Q.; Vincent, J.; Skaug, J.; Thompson, A.; Senman, L.; et al. Mapping autism risk loci using genetic linkage and chromosomal rearrangements. Nat. Genet. 2007, 39, 319-328.

25. Ching, M.S.L.; Shen, Y.; Tan, W.H.; Jeste, S.S.; Morrow, E.M.; Chen, X. Deletions of NRXN1 (neurexin-1) Predispose to a Wide Spectrum of Developmental Disorders. Am. J. Med. Genet. B Neuropsychiatry Genet. 2010, 153, 937-947. [CrossRef]

26. Dachtler, J.; Ivorra, J.L.; Rowland, T.E.; Lever, C.; Rodgers, R.J.; Clapcote, S.J. Heterozygous deletion of $\alpha$-neurexin I or $\alpha$-neurexin II results in behaviors relevant to autism and schizophrenia. Behav. Neurosci. 2015, 129, 765-776. [CrossRef]

27. Wiśniowiecka-Kowalnik, B.; Nesteruk, M.; Peters, S.U.; Xia, Z.; Cooper, M.L.; Savage, S.; Amato, R.S.; Bader, P.; Browning, M.F.; Haun, C.L.; et al. Intragenic rearrangements in NRXN1 in three families with autism spectrum disorder, developmental delay, and speech delay. Am. J. Med. Genet. B Neuropsychiatry Genet. 2010, 153, 983-993.

28. Sullivan, P.F.; Fan, C.; Perou, C.M. Evaluating the comparability of gene expression in blood and brain. Am. J. Med. Genet. B Neuropsychiatry Genet. 2006, 141, 261-268. [CrossRef]

29. Schmittgen, T.D.; Livak, K.J. Analyzing real-time PCR data by the comparative C(T) method. Nat. Protoc. 2008, 3, 1101-1108. [CrossRef]

30. Hamilton, M. A rating scale for depression. J. Neurol. Neurosurg. Psychiatry 1960, 23, 56-62. [CrossRef]

31. Bagby, R.M.; Ryder, A.G.; Schuller, D.R.; Marshall, M.B. The Hamilton Depression Rating Scale: Has the Gold Standard Become a Lead Weight? Am. J. Psychiatry. 2004, 161, 2163-2177. [CrossRef]

32. Kasem, E.; Kurihara, T.; Tabuchi, K. Neurexins and neuropsychiatric disorders. Neurosci. Res. 2018, 127, 53-60. [CrossRef]

33. Kirov, G.; Rujescu, D.; Ingason, A.; Collier, D.A.; O'Donovan, M.C.; Owen, M.J. Neurexin 1 (NRXN1) Deletions in Schizophrenia. Schizophr. Bull. 2009, 35, 851-885. [CrossRef]

34. Gandal, M.J.; Zhang, P.; Hadjimichael, E.; Walker, R.L.; Chen, C.; Liu, S.; Won, H.; Van Bakel, H.; Varghese, M.; Wang, Y.; et al. Transcriptome-wide isoform-level dysregulation in ASD, schizophrenia, and bipolar disorder. Science 2018, 362, eaat8127. [CrossRef]

35. Kumar, D.; Thakur, M.K. Age-related expression of Neurexin1 and Neuroligin3 is correlated with presynaptic density in the cerebral cortex and hippocampus of male mice. Age 2015, 37, 17. [CrossRef]

36. Fabbri, C.; Serretti, A. Genetics of long-term treatment outcome in bipolar disorder. Prog. Neuropsychopharmacol. Biol. Psychiatry 2016, 4, 17-24. [CrossRef]

37. Flaherty, E.; Zhu, S.; Barretto, N.; Cheng, E.; Deans, P.J.M.; Fernando, M.B.; Schrode, N.; Francoeur, N.; Antoine, A.; Alganem, K.; et al. Neuronal impact of patient-specific aberrant NRXN1 $\alpha$ splicing. Nat. Genet. 2019, 51, 1679-1690. [CrossRef] 
38. Souza, R.P.; Meltzer, H.Y.; Lieberman, J.A.; Le Foll, B.; Kennedy, J.L. Influence of neurexin 1 (NRXN1) polymorphisms in clozapine response. Hum. Psychopharmacol. 2010, 25, 582-585. [CrossRef]

39. Lett, T.A.; Tiwari, A.K.; Meltzer, H.Y.; Lieberman, J.A.; Potkin, S.G.; Voineskos, A.N.; Kennedy, J.L.; Müller, D.J. The putative functional rs1045881 marker of neurexin-1 in schizophrenia and clozapine response. Schizophr. Res. 2011, 132, 121-124. [CrossRef]

40. Lam, M.; Moslem, M.; Bryois, J.; Pronk, R.J.; Uhlin, E.; Ellström, I.D.; Laan, L.; Olive, J.; Morse, R.; Rönnholm, H.; et al. Single cell analysis of autism patient with bi-allelic NRXN1-alpha deletion reveals skewed fate choice in neural progenitors and impaired neuronal functionality. Exp. Cell Res. 2019, 383, 111469. [CrossRef]

41. Unalan, D.; Gocer, S.; Basturk, M.; Baydur, H.; Ozturk, A. Coincidence of low social support and high depressive score on quality of life in elderly. Eur. Geriatr. Med. 2015, 6, 319-324. [CrossRef] 